Article

\title{
The Impact of Erythrocytes Injury on Blood Flow in Bionic Arteriole with Stenosis Segment
}

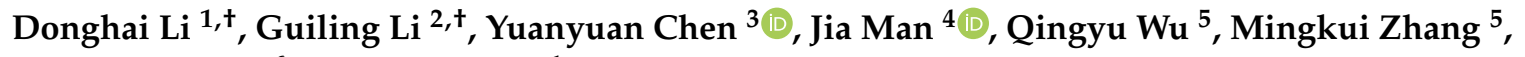 \\ Haosheng Chen ${ }^{6, *}$ and Yu Zhang ${ }^{1, *}$ \\ 1 School of Medicine, Tsinghua University, Beijing 100084,China; donghai_li10@163.com \\ School of Pharmaceutical Sciences, Tsinghua University, Beijing 100084, China; lgl@mail.tsinghua.edu.cn \\ 3 School of Mechanical Engineering and Automation, Beijing Advanced Innovation Center for Biomedical \\ Engineering, Beihang University, Beijing 100191, China; chenyuanyuan0526@sina.com \\ 4 School of Mechanical Engineering, Shandong University; Key Laboratory of High-efficiency and Clean \\ Mechanical Manufacture at Shandong University, Ministry of Education, Shandong 250061, China; \\ mj@sdu.edu.cn \\ 5 First Hospital of Tsinghua University, School of Medicine, Tsinghua University, Beijing 100084, China; \\ wuqingyu@mail.tsinghua.edu.cn (Q.W.); zhangmingkui@mail.tsinghua.edu.cn (M.Z.) \\ 6 School of Mechanical Engineering, State Key Laboratory of Tribology, Tsinghua University, \\ Beijing 100084, China \\ * Correspondence: chenhs@tsinghua.edu.cn (H.C.); yuzhang2014@tsinghua.edu.cn (Y.Z.) \\ + The two authors contributed equally to this work.
}

Received: 18 May 2019; Accepted: 11 June 2019; Published: 14 June 2019

check for updates

\begin{abstract}
Ventricular assist device (VAD) implantation is an effective treatment for patients with end-stage heart failure. However, patients who undergo long-term application of VADs experience a series of VAD-related adverse effects including pump thrombosis, which is induced by rotate impeller-caused blood cell injury and hemolysis. Blood cell trauma-related flow patterns are the key mechanism for understanding thrombus formation. In this study, we established a new method to evaluate the blood cell damage and investigate the real-time characteristics of blood flow patterns in vitro using rheometer and bionic microfluidic devices. The variation of plasma free hemoglobin $(\mathrm{PFH})$ and lactic dehydrogenase (LDH) in the rheometer test showed that high shear stress was the main factor causing erythrocyte membrane injury, while the long-term exposure of high shear stress further aggravated this trauma. Following this rheometer test, the damaged erythrocytes were collected and injected into a bionic microfluidic device. The captured images of bionic microfluidic device tests showed that with the increase of shear stress suffered by the erythrocyte, the migration rate of damaged erythrocyte in bionic microchannel significantly decreased and, meanwhile, aggregation of erythrocyte was clearly observed. Our results indicate that mechanical shear stress caused by erythrocyte injury leads to thrombus formulation and adhesion in arterioles.
\end{abstract}

Keywords: erythrocyte injury; flow pattern; bionic microfluidic device; thrombosis

\section{Introduction}

The concept of mechanical circulatory support (MCS) was developed rapidly to resolve the shortage of donor hearts for heart transplantation and the sustained increase of heart failure (HF) mobility and mortality. MCSs with ventricular assist devices (VADs) were originally designed as a temporary therapy for bridge-to-transplant (BTT). Nevertheless, VAD implantation is an efficacious treatment as a destination therapy for patients with end-stage $\mathrm{HF}$, which is refractory to current medical therapy and can effectively improve the long-time survival rate to approximately $81 \%$ and $70 \%$ at 1 year and 2 years, respectively [1,2]. The therapeutic benefits of VAD implantation are that it 
also improves the functional capacity and quality of life. However, patients who undergo long-term application of VADs experience a series of VAD-related adverse events, including right heart failure, pump thrombosis, gastrointestinal bleeding, driveline infection, stroke, and aortic insufficiency [2-10].

Among these VAD-related complications, thrombosis is concerning as a multifactorial complication which is related to other adverse events, such as hemolysis, stroke and bleeding, and can induce rapid clinical deterioration [11]. The mechanism of thrombosis has been studied for decades, and the induced factors of thrombosis lead to a decreased or turbulent flow pattern in VADs and suboptimal anticoagulation. Furthermore, hemolysis and von Willebrand deficiency, which are related to mechanical damage caused by rotate impellers, can also induce thrombosis. It is difficult to visualize the thrombosis in vivo. Therefore, various in vitro test methods and devices have been applied to monitor and evaluate blood clotting and platelet function to avoid thrombosis, such as assays for bleeding time, activated clotting time (ACT), activated partial thromboplastin time (APTT), thromboelastography, and platelet aggregometry. However, all of these parameters are tested under static or irrelevant flow conditions, which fail to incorporate the true flow pattern and status in blood vessels. Furthermore, the test devices are also quite different from actual vessel structures, especially the structure of stenosis arteries segments. Therefore, there is an urgent demand for a new method to investigate the real-time thrombus formation process and evaluate the relationship with the assessment of the blood cell damage in the region of VAD application.

Microfluidic devices, on which the blood flow pattern in simulated small vessels can be observed directly, have recently been used to study erythrocyte movement and blood flow in small vessels in vitro [12]. Based on bionic microfluidic devices, atherosclerotic confinement of vessels and blood flow patterns (including flow rate and physiological and pathological shear stress) in microscale arterioles can be simulated for basic combined research on whole blood and extracellular matrix surface coating or treatment [13-15]. However, the flow patterns were controlled by injecting flow rate and pressure, but were too coarse to maintain consistent inner shear stress force and flow rate in a device with several microscale channels. Furthermore, traces of experiment blood were difficult to collect and measure for the evaluation of the blood cell damage. In our previous research, the relations among erythrocyte morphology, membrane damage, and the concentration of specific plasma proteins had been revealed and confirmed, and the changes of plasma free hemoglobin (PFH) and lactic dehydrogenase (LDH) concentrations in plasma can be measured and analyzed to evaluate the degree of erythrocyte rupture and the degree of erythrocyte membrane injury, respectively [16]. Here, we collected fresh whole blood from sheep and exposed it to a fixed shear stress environment generated by a rheometer for blood cell damage assessment. Then, the damaged blood was collected and injected into a bionic microfluidic device, which was designed to mimic arterioles with several continuous stenosis segments, to investigate and evaluate the effects of red cell damage at different degrees on the flow pattern inside the microfluidic channel.

\section{Materials and Methods}

\subsection{Blood Collection}

Fresh total blood was collected from the jugular veins of 3 healthy adult male sheep (aged about 4 years old, with a body weight of around $80 \mathrm{~kg}$ ) for fixed shear stress and microfluidic channel tests. A large bore needle (16G) was applied to collect $400 \mathrm{~mL}$ blood into a $500 \mathrm{~mL}$ sterile PVC bag prefilled with $56 \mathrm{~mL}$ of citrate phosphate dextrose adenine (CPDA-1) anticoagulant; the procedure was performed according to American Society for Testing Materials (ASTM) Standard Practices F1830, and the aseptic technique was followed strictly. The fresh sheep blood was stored and transported with the temperature between 2 and $8{ }^{\circ} \mathrm{C}$, and the time interval from collection to experiment was within $8 \mathrm{~h}$. Before the experiment started, the collected sheep blood was kept quiescent in room temperature and rewarmed slowly to $24^{\circ} \mathrm{C}$ while maintaining the temperature of $37^{\circ} \mathrm{C}$ with a water bath during 
the experiment process. According to ASTM Standard Practices F1841, the hematocrit of blood applied in the tests was adjusted to $30 \%$ by a phosphate-buffered saline.

\subsection{Hemolysis Evaluation under Fixed Shear Stress}

A rheometer (MCR 310, Physica, Anton Paar GmbH, Graz, Austria) and coaxial cylinder testing mold CC27/E were applied to provide a well-defined test environment of fixed shear stress (Figure 1). The rotor and container were immersed in $75 \%$ ethanol for $5 \mathrm{~min}$ for sterilization and rinsed thoroughly with normal saline (NS) at the beginning of the experiment. NS was also used to rinse the residual blood at each test interval. Pre-warmed blood $(6 \mathrm{~mL})$ were slowly injected into containers for each testing. The gap between a rotor and container was set as $0.5 \mathrm{~mm}$ and the temperature of container was maintained at $37^{\circ} \mathrm{C}$. The shear stress was set as $0,25,50,75$ and $100 \mathrm{~Pa}$, with the exposure time of 5 , 10 and $15 \mathrm{~min}$. At the end of the tests, two $1.5 \mathrm{~mL}$ blood samples were collected from the bottom of the containers. Each blood sample was centrifuged twice at $3000 \mathrm{rpm}$ for $5 \mathrm{~min}$ at a temperature of $4{ }^{\circ} \mathrm{C}$. Supernatant was collected to measure the concentration of PFH and LDH, while the curves showing the changes of PFH and LDH concentrations over time at each shear stress gradient were also drawn.

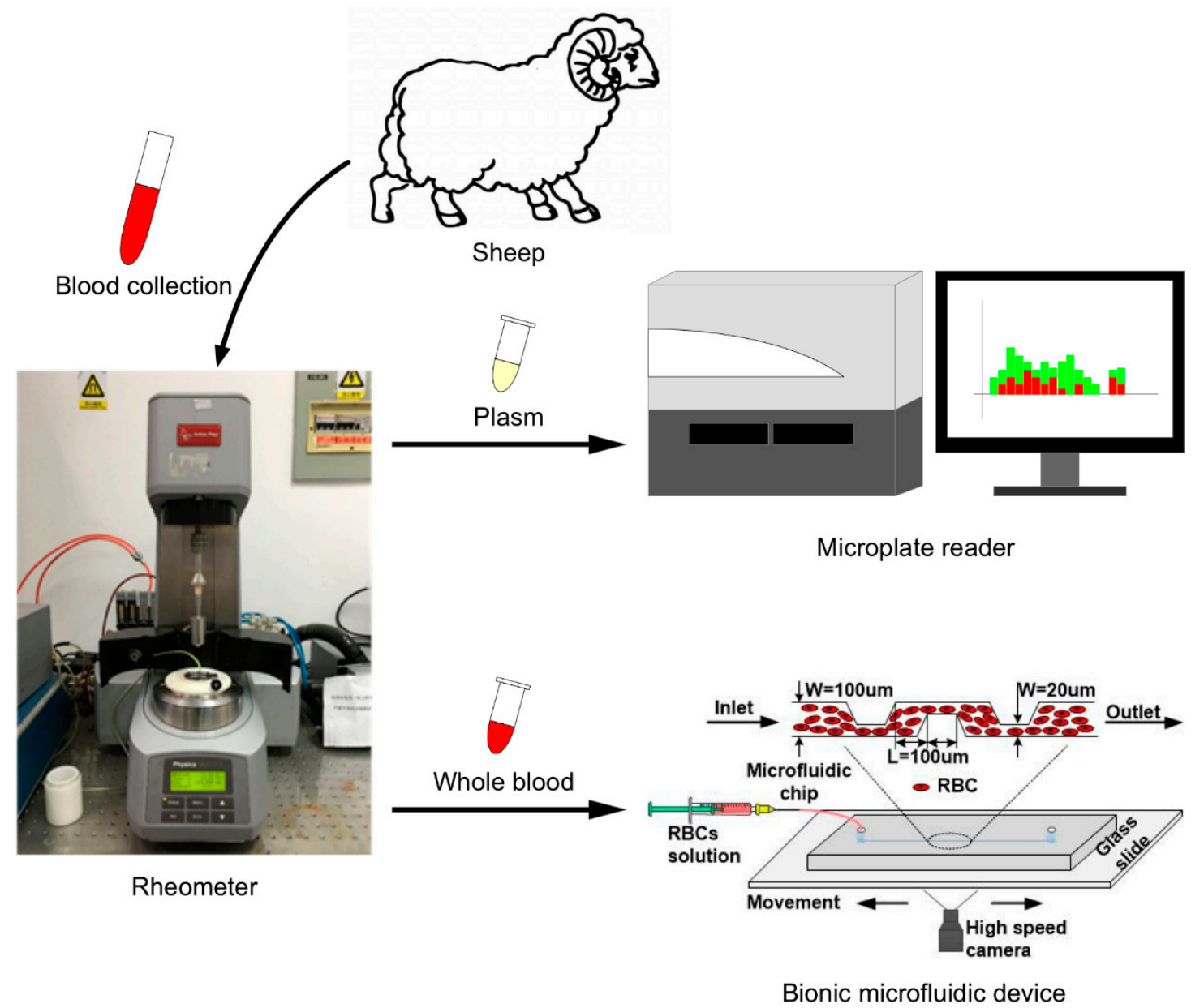

Figure 1. Schematics of the impact of erythrocytes injury caused by mechanical shear stress force on flow patterns in bionic arteriole with stenosis segment.

\subsection{Bionic Microfluidic Device Design and Visualization of Injected Erythrocyte Trajectories}

The bionic microfluidic channel was designed using AutoCAD software and fabricated through standard lithographic method [17]. The microfluidic device was composed of polydimethylsiloxane (PDMS) and a glass plate, which is one layer with the height of $20 \mu \mathrm{m}$, and the detailed channel parameters are shown in Figure 1. After exposed to stable shear stress on a rheometer platform for 
$10 \mathrm{~min}$, the whole blood sample was collected and injected into the inlet hole of the microchannel with the flow rate of $0.12 \mathrm{~mL} / \mathrm{min}$. The visualization of injected flowing erythrocyte trajectories in the microchannel were captured using a high-speed camera (M710, Phantom Co., New Jersey, USA) under the bright field provided by an inverted microscope (Leica DME6000 B, Leica Co., Wetzlar, Germany). The video analysis was processed using ImageJ software.

\subsection{Statistical Analysis}

The statistical analyses are performed with the one-way analysis of variance (ANOVA) using the prism software (GraphPad, San Diego, CA, USA). The data are reported as mean \pm standard error, and $p$-values of ${ }^{*} p<0.05,{ }^{* *} p<0.01,{ }^{* * *} p<0.001$ were considered statistically significant.

\section{Results}

\subsection{Variation of PFH Concentration with Gradient Change of Shear Stress and Exposure Time}

PFH is a classic label which is first applied to evaluate the red blood cell damage caused by VADs. The world-recognized CF-VADs testing process (American Society of Testing Materials Standard Practices F1830, ASTM F1841) and evaluation index, including normalized index of hemolysis $(\mathrm{NIH})$ and modified index of hemolysis $(\mathrm{MIH})$, were established on the basis of PFH concentration measurement. According to the curve of PFH concentration variation, shown in Figure $2 \mathrm{a}$, when the blood was exposed in a mechanical shear stress environment, within $5 \mathrm{~min}$, the concentrations of PFH release under 25 to $100 \mathrm{~Pa}$ rose synchronously without notable differences. When the exposure time increased up to $10 \mathrm{~min}$, the concentration of PFH rose rapidly in the group with 75 and 100 Pa shear stress. In particular, extremely high PFH releases were detected in the 75 and 100 Pa groups when the exposure time reached $15 \mathrm{~min}$. Meanwhile, as shown in Figure 2b, in a low shear stress environment (25 Pa and $50 \mathrm{~Pa}$ ), there were no significant changes of PFH concentration with the increasing of exposure time. However, in the high shear stress condition, especially under $100 \mathrm{~Pa}, \mathrm{PFH}$ release rose extremely high with the extension of exposure time. Therefore, long exposure time under high shear stress environment would induce more damage to erythrocytes.

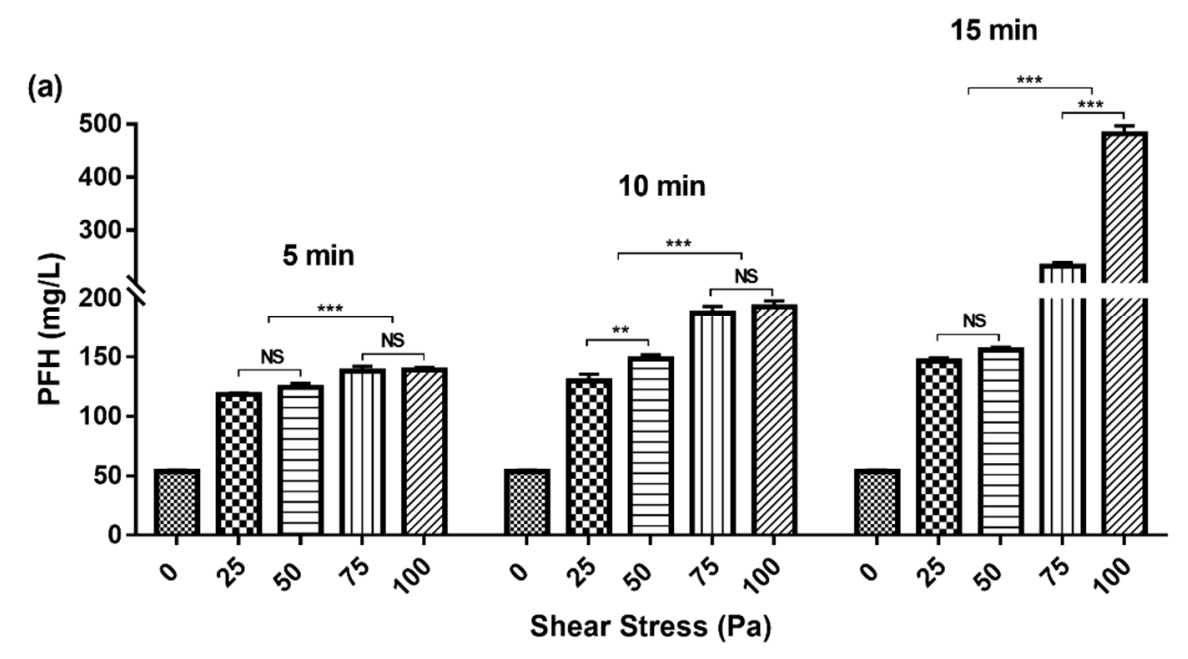

Figure 2. Cont. 


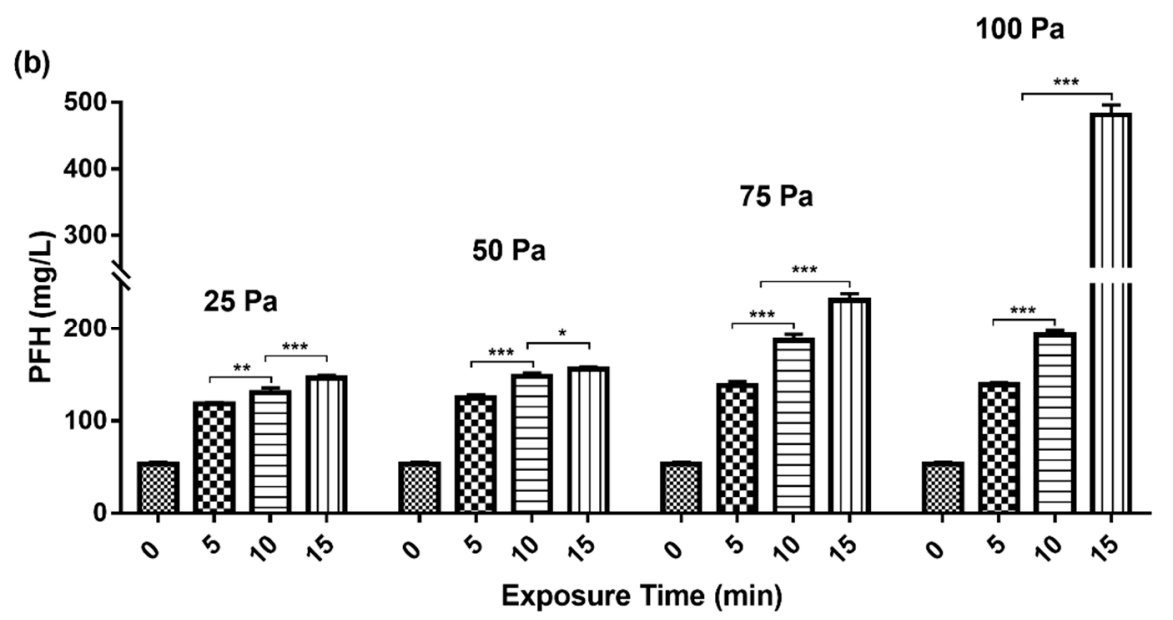

Figure 2. The changes of plasma plasma free hemoglobin (PFH) concentration under different shear stress and exposure times. (a) With the increase of shear stress, the concentration of PFH released into plasma showed a slow rising trend within $5 \mathrm{~min}$ and $10 \mathrm{~min}$, but with the extension of exposure time up to $15 \mathrm{~min}$, the concentration of PFH showed a rapid increase trend, especially in the shear stress of $100 \mathrm{~Pa}$. (b) With the increase of exposure time, the concentration of PFH released into plasma showed a slow rise trend at 25 and $50 \mathrm{~Pa}$, but the shear stress up to 75 and $100 \mathrm{~Pa}$, the concentration of PFH showed a rapid increase trend, especially in the exposure time $15 \mathrm{~min}$.

\subsection{LDH Release with Gradient Change of Shear Stress and Exposure Time}

Compared to $\mathrm{PFH}, \mathrm{LDH}$ is a novel and more sensitive protein label to assess the trauma of the erythrocyte membrane. Differently to $\mathrm{PFH}$ release based on erythrocyte rupture, injuries to the red blood cell membrane will induce an increase of LDH concentration in plasma. As the results show in Figure 3a, there was no significant difference in LDH release between the three groups with the exposure times of 5, 10, and $15 \mathrm{~min}$ in a low shear stress environment within $50 \mathrm{~Pa}$. The increase of LDH concentration was smooth and maintained a low level. However, when blood was exposed to a high shear stress condition (especially at $100 \mathrm{~Pa}$ ), the concentration of LDH rose rapidly with the increase of exposure time. Meanwhile, as the curve shows in Figure 3b, LDH release was insensitive to the prolonging of exposure time at low shear stress conditions in $25 \mathrm{~Pa}$ and $50 \mathrm{~Pa}$. However, the concentration of plasma LDH increased dramatically in a high shear stress environment, and the longer the exposure was, the greater the influence became. Therefore, high shear stress force was the main factor causing erythrocyte membrane injury, and the long exposure time could aggravate this trauma.

\subsection{Flow Patterns Monitoring with Bionic Microfluidic Devices}

After being exposed to a 25, 50, 75, and 100 Pa shear stress environment for $10 \mathrm{~min}$, blood samples were collected for the bionic microfluidic device test. The initial flow rate of blood sample injected into microfluidic devices was maintained as $0.12 \mathrm{~mL} / \mathrm{min}$ by a micropump. As shown in Figure 4, compared to the morphological characteristics of red blood cells (RBCs) exposed to 25 and $50 \mathrm{~Pa}$ shear stress force, more poikilocytes (characterized by sphericity), swelling, and multiple spines were found in the 75 and 100 Pa groups. The mean migration rate of erythrocytes at the posterior region of stenosis in the bionic microfluidic channel, which were subjected to $0,25,50,75$, and $100 \mathrm{~Pa}$ for $10 \mathrm{~min}$, were $467.55 \pm 74.16,444.39 \pm 41.82,354.43 \pm 46.93,250.91 \pm 34.67$, and $152.87 \pm 27.33 \mu \mathrm{m} / \mathrm{s}$, respectively. With the increase of shear stress force applied, the migration rate of damaged erythrocyte in the bionic microchannel declined significantly. However, the aggregation of RBCs rose notably with the increase to an exposed shear stress environment, which was synchronous with the degree of erythrocyte damage assessed previously. Moreover, thrombus was captured in the microchannel of the 75 and 100 Pa groups. The migration of thrombus and surrounding flow rate of 75 and 100 Pa groups 
were slower than the other two groups. These results indicate that slow flow patterns can also lead to thrombus deposition and adhesion in arterioles.
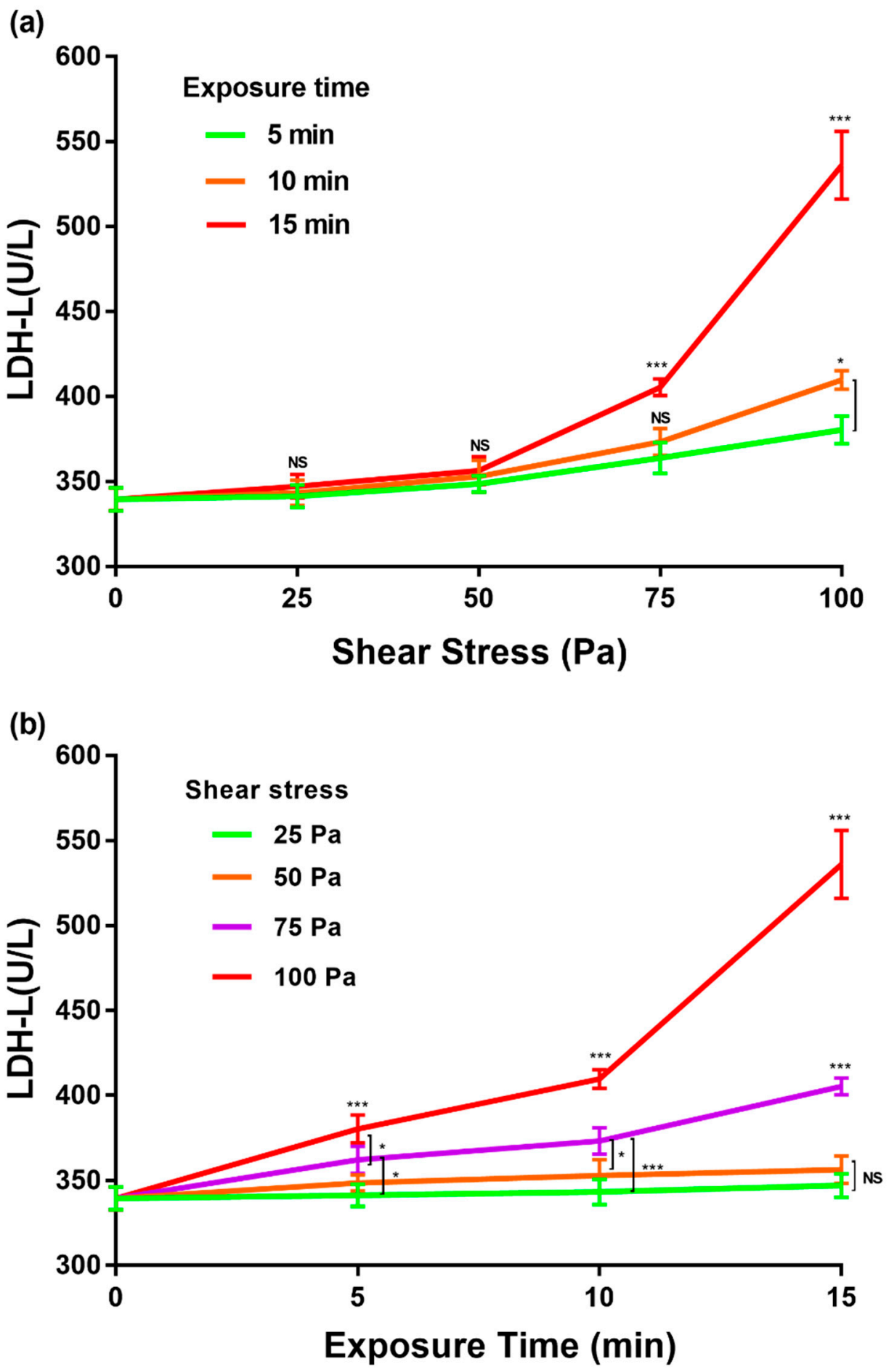

Figure 3. The changes of plasma lactic dehydrogenase (LDH) concentration under different shear stress and exposure times. (a) With the increase of shear stress, the concentration of plasma LDH showed an increase trend, especially above $50 \mathrm{~Pa}$, the $\mathrm{LDH}$ release presented a rapid raise; (b) With the extension of the exposure time, the concentration of plasma $\mathrm{LDH}$ in 25 and $50 \mathrm{~Pa}$ shear stress environments rose slowly, but in an $100 \mathrm{~Pa}$ environment, showed a rapid increase. 
$25 \mathrm{~Pa}$
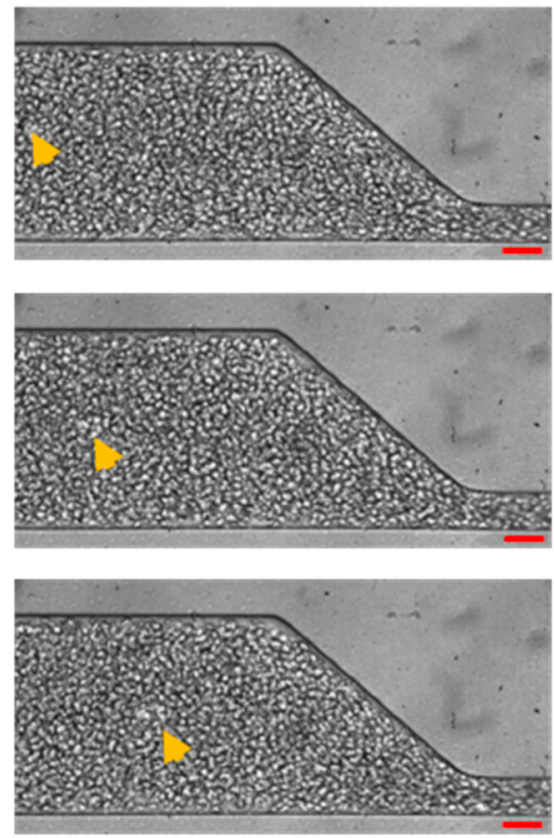

$75 \mathrm{~Pa}$
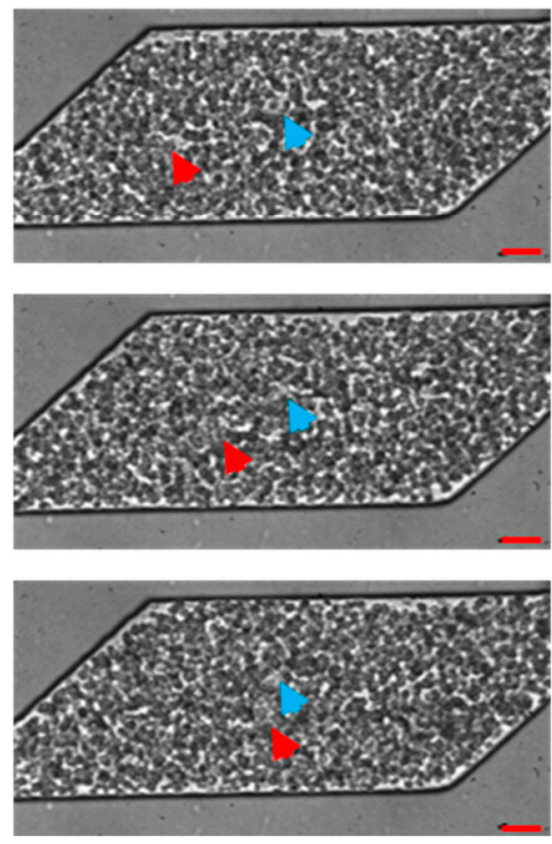

$50 \mathrm{~Pa}$
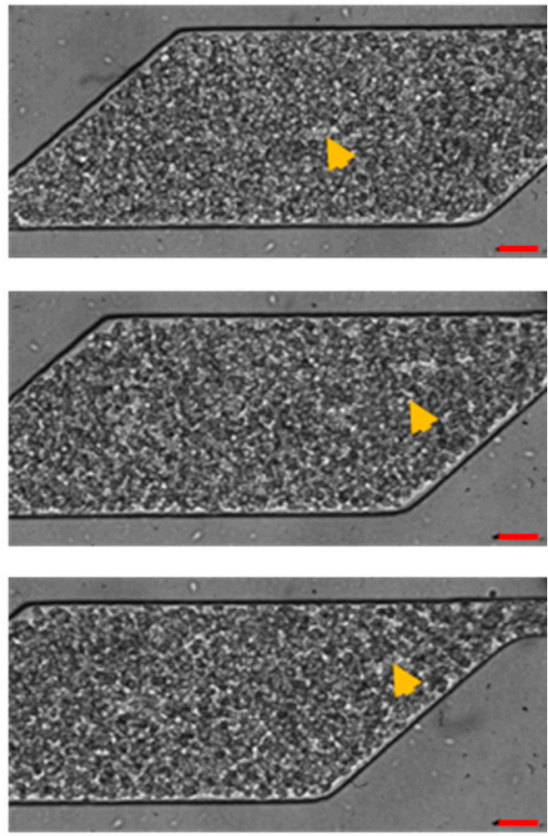

$100 \mathrm{~Pa}$
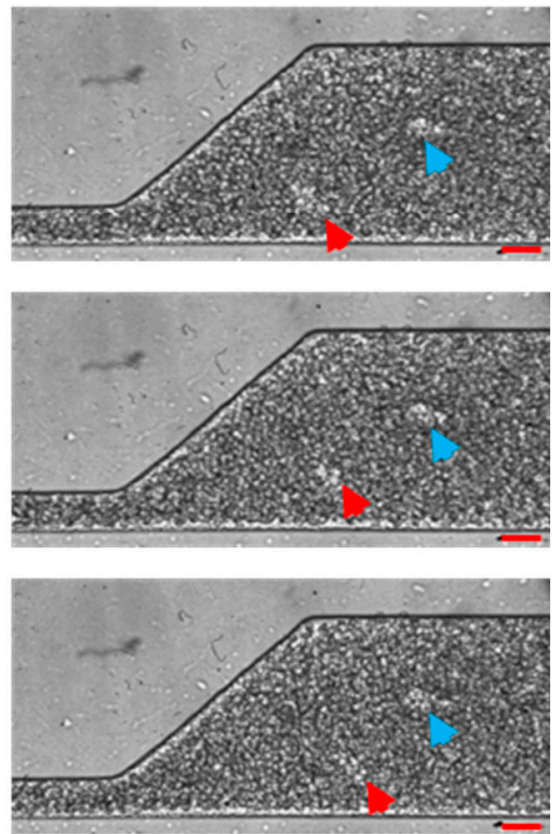

Figure 4. Migration rate and aggregation of damaged erythrocyte in microfluidic devices. All the blood samples were subjected to each shear stress environment for $10 \mathrm{~min}$. The initial flow rate injected into devices was $0.12 \mathrm{~mL} / \mathrm{min}$. With the increase of shear stress, the blood cell migration rate declined, but the aggregation increased. Yellow arrow: erythrocyte; Blue arrow: adhesion thrombus; Red arrow: moving thrombus (scale bar: $20 \mu \mathrm{m}$ ).

\section{Discussion}

Erythrocyte damage caused by high shear stress generated by the rotation of the inner impeller is the main problem of VADs that cannot be ignored, and has been demonstrated to induce damage of the erythrocyte membrane, increase cellular fragility, reduce deformability, enhance aggregation 
and, finally, increase the risk of intervascular hemolysis and thrombosis [18]. The variation of PFH and LDH in the rheometer tests showed that high shear stress was the main factor causing red blood cell membrane injury. This result is consistent with our previous observations, and an effective interpretation of the influence of shear stress force on hemolysis [19]. Meanwhile, with the increase of exposure time in a fixed shear stress environment, the release of PFH and LDH rose gradually. This is consistent with the phenomenon reported by Shimono, that a lot of erythrocytes were suddenly ruptured in the long-term in vitro hemolysis tests [20]. The result indicated the cumulative damage of erythrocyte membrane increased with the extension of exposure time and, finally, aggravated the occurrence of hemolysis.

Increased blood viscosity, effects on the vessel wall, platelet activation, and thrombin generation, and the effects of fibrinogen and fibrin are established risk factors for thrombosis [21]. Blood consists of a large number of blood cells suspended in plasma. The total of white cells and platelets occupy less than $1 \%$ of blood volume, while RBCs are the dominant component of the blood, accounting for $40 \%-45 \%$ of blood volume [18]. Growing evidence suggests erythrocytes contribute to blood thrombosis because erythrocytes mediate blood rheology, interact with fibrinogen and fibrin, interact with other cells, and also support thrombin generation [22]. The rheological properties of blood are primarily governed by the concentration of RBCs, size, sharpness, deformability, intrinsic viscoelastic properties and fibrinogen-binding ability [23-25]. Therefore, the investigation of blood flow rheology and thrombus generation process directly in arterioles and its relationship with blood cell trauma under high shear stress environments is the key mechanism for research of thrombus formation. However, it is difficult to identify the mechanisms of thrombosis in clinical and epidemiologic studies, due to inaccurate identification of causation. Moreover, previous in vivo studies based on animal models, it was also difficult to interpret the effects of erythrocyte on thrombosis, due to the preparation and evaluation of the injured erythrocyte and the limitations of current observation techniques. Thus, microfluidic devices are applied to observe the dynamic movement patterns of erythrocyte. Previous microfluidic device experiments have confirmed that thrombosis can be induced by blood contact with exogenous materials and local flow conditions [26-28]. These studies depended on the parallel plate channel structure on microfluidic devices to provide similar arteriolar flow conditions in live vasculature. It is impossible to control the effect of specific shear stress on RBCs in the microchannel. Previous studies have shown that exposure to shear stress environments would induce erythrocyte membrane injury, resulting in swelling, irregular deformation, and reduce deformability. This phenomenon can also be observed directly in this research. All of these, especially when the stenosis of the blood vessel affects the blood fluid rheology, will aggravate the erythrocyte aggregation and eventually accelerate thrombosis. In this project, the erythrocyte damage in a fixed shear stress environment has been evaluated. The variations of flow patterns in bionic microchannels reflected accurately the effect of erythrocyte injury on aggregation ability and the flow state in small vessels. The captured images of bionic microfluidic device tests show that there was no significant difference for the migration rate at 0 and $25 \mathrm{~Pa}(p=0.52>0.05)$. However, significant differences were found between other groups $(p<0.01)$. The results indicate that with an increase of shear stress suffered by the erythrocyte, the migration rate of damaged erythrocyte in bionic microchannels significantly decreased. Meanwhile the aggregation of erythrocyte was clearly observed in 75 and 100 Pa groups. The results indicate that mechanical shear stress caused by erythrocyte injury, which enhanced aggregation ability of erythrocytes and increased blood viscosity, resulted in decreased blood rheological performance, eventually leading to thrombus formulation and adhesion in arterioles.

\section{Conclusions}

In this study, we used rheometer and bionic microfluidic devices to investigate and evaluate the effect of injury erythrocytes on flow patterns in bionic arterioles with stenosis segment. The variation of PFH concentration under different shear stress and exposure time in rheometers showed that the long exposure time in high shear stress environments would induce more damage of erythrocytes. 
Meanwhile, LDH release with gradient changes under different shear stress and exposure times revealed that high shear stress was the main factor causing erythrocyte membrane injury, and a long exposure time could aggravate this trauma. Following this rheometer test, the damaged erythrocytes were collected and injected into a bionic microfluidic device which was designed to mimic arterioles with several continuous stenosis segments, to investigate and evaluate the flow pattern modification by red cell damage at different degrees. The results show that with the increase of shear stress, the migration rate of damaged erythrocyte declined and the aggregation of erythrocyte was clearly observed in bionic microchannels, which was consistent with the degree of erythrocyte damage assessed through the rheometer test. Our results indicate that mechanical shear stress was caused by erythrocyte injury, which enhanced aggregation ability of erythrocytes and increased blood viscosity and resulted in decreased blood rheological performance, eventually leading to thrombus formulation and adhesion in arterioles.

Author Contributions: D.L. and G.L. developed the concept of the article and wrote the outline of the paper draft; Y.Z. supported work in funding and reviewed the paper; H.C. reviewed the paper; Y.C. and J.M. analyzed the data; Q.W. and M.Z. redacted the paper. All authors of this article provided substantive comments.

Funding: This research was funded by Tsinghua University Initiative Scientific Research Program, grant number 20141081265.

Acknowledgments: Guiling Li acknowledges the support from Center for Life Sciences at Tsinghua and Peking Universities. Jia Man acknowledges the support from Key Laboratory of High-efficiency and Clean Mechanical Manufacture at Shandong University, Ministry of Education.

Conflicts of Interest: The authors declare no conflict of interest.

\section{References}

1. Slaughter, M.S.; Rogers, J.G.; Milano, C.A.; Russell, S.D.; Conte, J.V.; Feldman, D.; Sun, B.; Tatooles, A.J.; Delgado, R.M., 3rd; Long, J.W.; et al. Advanced heart failure treated with continuous-flow left ventricular assist device. N. Engl. J. Med. 2009, 361, 2241-2251. [CrossRef] [PubMed]

2. Kirklin, J.K.; Pagani, F.D.; Kormos, R.L.; Stevenson, L.W.; Blume, E.D.; Myers, S.L.; Miller, M.A.; Baldwin, J.T.; Young, J.B.; Naftel, D.C. Eighth annual INTERMACS report: Special focus on framing the impact of adverse events. J. Heart Lung Transplant. 2017, 36, 1080-1086. [CrossRef] [PubMed]

3. Kapur, N.K.; Esposito, M.L.; Bader, Y.; Morine, K.J.; Kiernan, M.S.; Pham, D.T.; Burkhoff, D. Mechanical Circulatory Support Devices for Acute Right Ventricular Failure. Circulation 2017, 136, 314-326. [CrossRef] [PubMed]

4. Kirklin, J.K.; Naftel, D.C.; Pagani, F.D.; Kormos, R.L.; Myers, S.; Acker, M.A.; Rogers, J.; Slaughter, M.S.; Stevenson, L.W. Pump thrombosis in the Thoratec HeartMate II device: An update analysis of the INTERMACS Registry. J. Heart Lung Transpl. 2015, 34, 1515-1526. [CrossRef] [PubMed]

5. Najjar, S.S.; Slaughter, M.S.; Pagani, F.D.; Starling, R.C.; McGee, E.C.; Eckman, P.; Tatooles, A.J.; Moazami, N.; Kormos, R.L.; Hathaway, D.R.; et al. An analysis of pump thrombus events in patients in the HeartWare ADVANCE bridge to transplant and continued access protocol trial. J. Heart Lung Transplant. 2014, 33, $23-34$. [CrossRef] [PubMed]

6. Goldstein, D.J.; Aaronson, K.D.; Tatooles, A.J.; Silvestry, S.C.; Jeevanandam, V.; Gordon, R.; Hathaway, D.R.; Najarian, K.B.; Slaughter, M.S.; Investigators, A. Gastrointestinal bleeding in recipients of the HeartWare Ventricular Assist System. JACC Heart Fail. 2015, 3, 303-313. [CrossRef] [PubMed]

7. Joy, P.S.; Kumar, G.; Guddati, A.K.; Bhama, J.K.; Cadaret, L.M. Risk Factors and Outcomes of Gastrointestinal Bleeding in Left Ventricular Assist Device Recipients. Am. J. Cardiol. 2016, 117, 240-244. [CrossRef] [PubMed]

8. Willey, J.Z.; Gavalas, M.V.; Trinh, P.N.; Yuzefpolskaya, M.; Reshad Garan, A.; Levin, A.P.; Takeda, K.; Takayama, H.; Fried, J.; Naka, Y.; et al. Outcomes after stroke complicating left ventricular assist device. J. Heart Lung Transplant. 2016, 35, 1003-1009. [CrossRef]

9. Cowger, J.; Rao, V.; Massey, T.; Sun, B.; May-Newman, K.; Jorde, U.; Estep, J.D. Comprehensive review and suggested strategies for the detection and management of aortic insufficiency in patients with a continuous-flow left ventricular assist device. J. Heart Lung Transpl. 2015, 34, 149-157. [CrossRef] 
10. Jorde, U.P.; Uriel, N.; Nahumi, N.; Bejar, D.; Gonzalez-Costello, J.; Thomas, S.S.; Han, J.; Morrison, K.A.; Jones, S.; Kodali, S.; et al. Prevalence, Significance, and Management of Aortic Insufficiency in Continuous Flow Left Ventricular Assist Device Recipients. Circ Heart Fail. 2014, 7, 310-319. [CrossRef]

11. Uriel, N.; Han, J.; Morrison, K.A.; Nahumi, N.; Yuzefpolskaya, M.; Garan, A.R.; Duong, J.; Colombo, P.C.; Takayama, H.; Thomas, S.; et al. Device thrombosis in HeartMate II continuous-flow Left ventricular assist devices: A multifactorial phenomenon. J. Heart Lung Transplant. 2014, 33, 51-59. [CrossRef] [PubMed]

12. Jain, A.; Graveline, A.; Waterhouse, A.; Vernet, A.; Flaumenhaft, R.; Ingber, D.E. A shear gradient-activated microfluidic device for automated monitoring of whole blood haemostasis and platelet function. Nat. Commun. 2016, 7, 10176. [CrossRef] [PubMed]

13. Westein, E.; van der Meer, A.D.; Kuijpers, M.J.; Frimat, J.P.; van den Berg, A.; Heemskerk, J.W. Atherosclerotic geometries exacerbate pathological thrombus formation poststenosis in a von Willebrand factor-dependent manner. Proc. Natl. Acad. Sci. USA 2013, 110, 1357-1362. [CrossRef] [PubMed]

14. Li, M.; Hotaling, N.A.; Ku, D.N.; Forest, C.R. Microfluidic thrombosis under multiple shear rates and antiplatelet therapy doses. PLoS ONE 2014, 9, e82493. [CrossRef]

15. Para, A.N.; Ku, D.N. A low-volume, single pass in-vitro system of high shear thrombosis in a stenosis. Thromb. Res. 2013, 131, 418-424. [CrossRef] [PubMed]

16. Li, D.; Wu, Q.; Liu, S.; Chen, Y.; Chen, H.; Ruan, Y.; Zhang, Y. Lactic Dehydrogenase in the In Vitro Evaluation of Hemolytic Properties of Ventricular Assist Device. Artif. Organs 2017, 41, E274-E284. [CrossRef] [PubMed]

17. McDonald, J.C.; Duffy, D.C.; Anderson, J.R.; Chiu, D.T.; Wu, H.K.; Schueller, O.J.A.; Whitesides, G.M. Fabrication of microfluidic systems in poly(dimethylsiloxane). Electrophoresis 2000, 21, 27-40. [CrossRef]

18. Baskurt, O.u.K. Handbook of Hemorheology and Hemodynamics; IOS Press: Amsterdam, The Netherlands; Washington, DC, USA, 2007; 455p.

19. Li, D.H.; Wu, Q.Y.; Ji, J.J.; Liu, S.H.; Zhang, M.K.; Zhang, Y. Hemolysis in a continuous-flow ventricular assist device with/without chamfer. Adv. Mech. Eng. 2017, 9. [CrossRef]

20. Shimono, T.; Makinouchi, K.; Nose, Y. Total Erythrocyte Destruction Time - the New Index for the Hemolytic Performance of Rotary Blood Pumps. Artif. Organs 1995, 19, 571-575. [CrossRef] [PubMed]

21. Byrnes, J.R.; Wolberg, A.S. Red blood cells in thrombosis. Blood 2017. [CrossRef] [PubMed]

22. Walton, B.L.; Byrnes, J.R.; Wolberg, A.S. Fibrinogen, red blood cells, and factor XIII in venous thrombosis. J. Thromb. Haemost. 2015, 13 (Suppl. 1), S208-S215. [CrossRef] [PubMed]

23. Lowe, G.D.; Lee, A.J.; Rumley, A.; Price, J.F.; Fowkes, F.G. Blood viscosity and risk of cardiovascular events: The Edinburgh Artery Study. Br. J. Haematol. 1997, 96, 168-173. [CrossRef] [PubMed]

24. Holley, L.; Woodland, N.; Hung, W.T.; Cordatos, K.; Reuben, A. Influence of fibrinogen and haematocrit on erythrocyte sedimentation kinetics. Biorheology 1999, 36, 287-297. [PubMed]

25. Rampling, M.W. The binding of fibrinogen and fibrinogen degradation products to the erythrocyte membrane and its relationship to haemorheology. Acta Biol. Med. Ger. 1981, 40, 373-378. [PubMed]

26. Neeves, K.B.; Onasoga, A.A.; Hansen, R.R.; Lilly, J.J.; Venckunaite, D.; Sumner, M.B.; Irish, A.T.; Brodsky, G.; Manco-Johnson, M.J.; Di Paola, J.A. Sources of variability in platelet accumulation on type 1 fibrillar collagen in microfluidic flow assays. PLoS ONE 2013, 8, e54680. [CrossRef] [PubMed]

27. Hosokawa, K.; Ohnishi, T.; Kondo, T.; Fukasawa, M.; Koide, T.; Maruyama, I.; Tanaka, K.A. A novel automated microchip flow-chamber system to quantitatively evaluate thrombus formation and antithrombotic agents under blood flow conditions. J. Thromb. Haemost. 2011, 9, 2029-2037. [CrossRef] [PubMed]

28. Westein, E.; de Witt, S.; Lamers, M.; Cosemans, J.M.; Heemskerk, J.W. Monitoring in vitro thrombus formation with novel microfluidic devices. Platelets 2012, 23, 501-509. [CrossRef] [PubMed]

(C) 2019 by the authors. Licensee MDPI, Basel, Switzerland. This article is an open access article distributed under the terms and conditions of the Creative Commons Attribution (CC BY) license (http://creativecommons.org/licenses/by/4.0/). 